SPECIAL

COMMUNICATION-

Volume 12 Issue 42020

DOI: 10.21315/eimj2020.12.4.4

ARTICLE INFO

Submitted: 07-08-2020

Accepted: 21-08-2020

Online: 30-12-2020

\section{Recommendations for High-Stakes Examinations for Public Malaysian Medical Faculties during the COVID-19 Pandemic}

Kamarul Aryffin Baharuddin', Ahmad Fuad Abdul Rahim ${ }^{2}$, Yang Faridah Abdul Aziz ${ }^{3}$, Roslina Abdul Manap ${ }^{4}$, Ahmad Marzuki Omar ${ }^{5}$, Nariman Singmamae ${ }^{6}$, Noor Fadzilah Zulkifli', Salwani Ismail ${ }^{8}$, Effat Omar $^{9}$, Fairrul Kadir ${ }^{10}$, Norhafizah Mohtarrudin ${ }^{11}$, Mohd Azhar Mohd Noor ${ }^{12}$, Muhd Al-Aarifin Ismail ${ }^{2}$, Mohamad Najib Mat Pa ${ }^{2}$, Zul Izhar Mohd Ismail ${ }^{13}$, Nik Ahmad Zuky Nik Lah ${ }^{14}$

${ }^{1}$ Department of Emergency Medicine, School of Medical Sciences,
Universiti Sains Malaysia, Kelantan, MALAYSIA
${ }^{2}$ Department of Medical Education, School of Medical Sciences,
Universiti Sains Malaysia, Kelantan, MALAYSIA
${ }^{3}$ Faculty of Medicine, Universiti Malaya, Kuala Lumpur,
MALAYSIA
${ }^{4}$ Faculty of Medicine, Universiti Kebangsaan Malaysia, Kuala
Lumpur, MALAYSIA

${ }^{5}$ Kulliyyah of Medicine, International Islamic University Malaysia, Pahang, MALAYSIA

${ }^{6}$ Faculty of Medicine and Health Sciences, Universiti Malaysia Sarawak, Sarawak, MALAYSIA

${ }^{7}$ Faculty of Medicine and Health Sciences, Universiti Sains Islam Malaysia, Kuala Lumpur, MALAYSIA

${ }^{8}$ Faculty of Medicine, Universiti Sultan Zainal Abidin, Terengganu, MALAYSIA

${ }^{9}$ Faculty of Medicine and Institute of Pathology, Laboratory and Forensic Medicine (I-PPerForM), Universiti Teknologi MARA, Sungai Buloh Campus, Selangor, MALAYSIA

${ }^{10}$ Faculty of Medicine and Health Sciences, Universiti Malaysia Sabah, Sabah, MALAYSIA

${ }^{11}$ Faculty of Medicine and Health Sciences, Universiti Putra Malaysia, Selangor, MALAYSIA

${ }^{12}$ Faculty of Medicine and Defence Health, Universiti Pertahanan Nasional Malaysia, Kuala Lumpur, MALAYSIA

${ }^{13}$ Department of Anantomy, School of Medical Sciences, Universiti Sains Malaysia, Kelantan, MALAYSIA

${ }^{14}$ Department of Obstetrics and Gynaecology, School of Medical Sciences, Universiti Sains Malaysia, Kelantan, MALAYSIA

To cite this article: Baharuddin KA, Abdul Rahim AF, Abdul Aziz YF, Abdul Manap R, Omar AM, Singmamae N, Zulkifli NF, Ismail S, Omar E, Kadir F, Mohtarrudin N, Mohd Noor MA, Ismail MAA, Mat Pa MN, Mohd Ismail ZI, Nik Lah NAZ. Recommendations for high-stakes examinations for public Malaysian medical faculties during the COVID-19 pandemic. Education in Medicine Journal. 2020;12(4):25-31. https://doi.org/10.21315/eimj2020.12.4.4

To link to this article: https://doi.org/10.21315/eimj2020.12.4.4 


\section{ABSTRACT}

The COVID-19 pandemic forced the Deans' Council of Public Malaysian Medical Faculties to tackle the issue of examinations in the face of movement control orders (MCO). A task force decided that final professional examination is necessary and three recommendations have been proposed. Online examination is among the best option with strict adherence to the Malaysian Medical Council guidelines. The majority of the universities used a Moodle-based Learning Management System; the examination will therefore mainly cover cognitive outcomes focusing on final professional exit examinations. It felt that cheating, although a real issue, is manageable and came up with several recommendations for the implementation based on likely outcomes of the MCO.

Keywords: High-stakes examination, Online, Medical education, Pandemic

Kamarul Aryffin Baharuddin, Department of Emergency Medicine, School of Medical Sciences, Universiti Sains Malaysia, 16150 Kubang Kerian, Kelantan, Malaysia | Email: amararyff@usm.my

\section{INTRODUCTION}

Changes are inevitable; what was normal yesterday may not be so today. During the current COVID-19 pandemic, the term "new normal" became popular to describe the new way we socialise, work, learn and live our lives. Medical education is also not exempted from this new normal. Social distancing, movement control order (MCO) and a ban on mass gatherings caused many medical faculties to temporarily halt their operations while reassessing the situation and strategising the best way to move forward. Nevertheless, these invisible forces have given us the fortuity to empower our online teaching and learning activities.

Synchronous and asynchronous online teaching became a norm in the new normal. Video conferencing platforms like Zoom, Cisco Webex, Microsoft Teams and others have become the platform for synchronous online learning. Many medical educators enjoy it but a few find it somewhat vexing. However, the final hurdle that medical educators need to leap over is the conduct of the examination, either theory or clinical examinations, whenever it is due.

In Malaysia, the first case of COVID-19 was reported on 25th January 2020 (1) and the first MCO was enforced on 18th March 2020 (2), which includes mandatory closure of higher education institutions.
In response, on 22nd April 2020, the Deans' Council of Public Malaysian Medical Faculties formed a task force comprising all academic deputy deans of 11 participating medical faculties and representatives from medical education departments. This task force was given the responsibility to look at the feasibility of online examinations for medical programmes in Malaysia during the pandemic and provide recommendations for the Deans' Council of Public Malaysian Medical Faculties.

This article reports on the various issues discussed by the task force and the recommendations it made regarding the assessment.

\section{ISSUES DISCUSSED}

\section{Learning Management System}

To achieve a level of standardisation amongst the medical faculties, the learning management system (LMS) used by each university was identified. An LMS is a software application used for delivery of an online educational course, including assessments. Table 1 shows that all universities have an LMS; Moodle being the most popular. By having an established LMS, theory examinations should be able to be conducted online. 
Table 1: LMS of the public universities in Malaysia

\begin{tabular}{lll}
\hline University & LMS & Name \\
\hline Universiti of Malaya & Moodle & SPeCTRUM \\
Universiti Sains Malaysia & Moodle & eLearn@USM \\
Universiti Kebangsaan Malaysia & Moodle & UKMFolio \\
International Islamic University Malaysia & Moodle & iTa'LeEM \\
Universiti Putra Malaysia & Moodle & PutraBLAST, PutraMOOC \\
Universiti Malaysia Sarawak & Moodle & UNIMAS eLeap \\
Universiti Malaysia Sabah & Moodle & smart3V \\
Universiti Teknologi MARA & Home-grown & i-Learn \\
Universiti Sains Islam Malaysia & Moodle & GOALS \\
Universiti Sultan Zainal Abidin & Moodle & e-KeLIP \\
Universiti Pertahanan Nasional Malaysia & Moodle & eLearningv2 UPNM \\
\hline
\end{tabular}

\section{Coverage of Learning Outcomes by Online Assessment}

Learning outcomes define what a student should know or can do as the focal point of the learning process (3). Accordingly, assessments should reflect the learning outcomes and provide essential assurance to a wide variety of stakeholders. However, with the current situation, flexibility to redesign the assessment should be contemplated.
Learning outcomes are commonly classified using the Bloom taxonomy into cognitive, psychomotor and affective domains (4). Valid assessment of the psychomotor and affective domains, particularly in clinical performance assessments using online methods is difficult as it involves face-to-face observations (5). However, the assessment of certain components of clinical skills such as history-taking and management might be possible. Table 2 shows examples of various possible online assessment modalities for various types of clinical learning outcomes.

Table 2: Competency domains of clinical learning outcomes and possible online assessment modalities

\begin{tabular}{|c|c|c|c|}
\hline \multirow{2}{*}{ Clinical learning outcomes } & \multicolumn{3}{|c|}{ Online assessment modalities } \\
\hline & Cognitive & Psychomotor & Affective \\
\hline Application of knowledge & MCQ, MEQ, SBQ & & \\
\hline \multicolumn{4}{|l|}{ Problem solving } \\
\hline Clinical reasoning & Online clinical viva & & \\
\hline \multicolumn{4}{|l|}{ Ethical reasoning } \\
\hline \multicolumn{4}{|l|}{ Diagnostic ability } \\
\hline \multicolumn{4}{|l|}{ Patient management } \\
\hline History taking skills & \multirow{2}{*}{\multicolumn{3}{|c|}{$\begin{array}{l}\text { Online history taking } \\
\text { (real/simulated patients) }\end{array}$}} \\
\hline Communication skills & & & \\
\hline Physical examination & & $\begin{array}{l}\text { Pre-recorded video } \\
\text { (students demonstrate } \\
\text { physical examination) + } \\
\text { online mini clinical viva }\end{array}$ & \\
\hline
\end{tabular}


Table 2: (continued)

\begin{tabular}{|c|c|c|c|}
\hline \multirow{2}{*}{ Clinical learning outcomes } & \multicolumn{3}{|c|}{ Online assessment modalities } \\
\hline & Cognitive & Psychomotor & Affective \\
\hline Professionalism & & & $\begin{array}{l}\text { Online clinical viva } \\
\text { Pre-recorded } \\
\text { video (students } \\
\text { demonstrate } \\
\text { physical } \\
\text { examination) }\end{array}$ \\
\hline
\end{tabular}

Notes: MCQ: Multiple choice questions; MEQ: Multiple essay questions; SBQ: Scenario-based questions.

\section{High-Stakes Examinations}

The task force focused mainly on highstakes examinations, namely professional examinations since they are the basis for major decisions (6). The final professional examination is an exit examination where a graduate shall demonstrate competency in all the outcomes (7). The components of the examination include the theory component which mainly focuses on the cognitive domain; and the clinical component which focuses on psychomotor and affective domains. The final professional examination is regarded as the most difficult examination by the majority of medical students as they must be able to integrate all the domains efficiently.

\section{Issues with Online Examination}

Several issues have been identified by the task force. First, the conduct of the online examination must be synchronous or simultaneous for all students involved to minimise cheating. Hence, internet connectivity must be optimum. During the conditional MCO, students are allowed to find better internet coverage, therefore, the task force hopes that this issue will be minimised.

The second issue is the security of the LMS, as the students are not staying in one centre and therefore, the environment during the conduct of the examination is beyond the control of the universities. This situation might induce cheating among candidates, which is a validity threat (8). The Malaysian Medical Council (MMC) has provided a guideline to minimise cheating during non-proctored and proctored online examinations (9). Shuffling of the questions and the answer's options are also ways to reduce cheating. The hard truth is that cheating among medical students is often, no matter in which format (10). Apart from the measures described, nurturing honesty among students should be an important strategy $(11,12)$.

The task force has also decided that each university will provide logistical and internet support to all nearby students regardless of their parent university should interstate travel be disallowed for students. This could also mitigate the risk of poor internet connectivity and validity threats.

Another issue is the assessment of psychomotor domain during the examination. Creative methods may be required for the assessment but still limited to the cognitive aspects of clinical skills (13).

\section{Recommendations of the Task Force Regarding Examinations}

Despite countries like Italy and UK skipping final year medicine examinations to allow their final year students to join the frontliners $(14,15)$, the task force feels that the urgency is not present in Malaysia and the final professional examination will still be conducted. The task force has come out with three recommendations to the Deans' Council of Public Malaysian Medical Faculties to decide. These recommendations still depend on the continuation or cessation of the MCO and updates by the National 
Security Council and the Ministry of Higher Education.

(a) Recommendation 1 is based on the situation where the MCO is lifted in June 2020. Students will return to the campus and the examination will be conducted with strict measures to prevent the spread of COVID-19. The date for professional examinations are unchanged (August to October 2020), depending on each university.

(b) Recommendation 2 is based on the situation where the MCO is extended and students are not allowed to return to the campus until a later date. The period for the professional examinations is unchanged. In this scenario, the conduct of the examination will be fully online, adhering to the MMC Online Exam Guidelines. The task force decided not to accept pre-recorded videos as students might not be comfortable to speak and act in front of the camera, as well as differences among students regarding technology skills.

To certify the clinical competency of the graduates, a refresher or supplementary course will be conducted before their internship placement. If assessment data from the candidates' previous postings could be retrieved, it could also be considered as indicators of their clinical competency (16).

(c) Recommendation 3 is also based on the situation where the MCO is extended and students are not allowed to return to the campus. However, in this scenario, the final professional examination will be deferred to a later date, probably in early 2021. Universities may consider conducting theory examinations online at an earlier date. Those who pass will be awarded a conditional pass until they sit for their clinical examination in early 2021.

\section{CONCLUSION}

The impact scale of the present COVID-19 pandemic is unprecedented in recent history. Despite that, the Deans' Council of Public Malaysian Medical Faculties was able to convene and come up, via the task force, with tentative plans to face the situation. In hindsight, this parallels the " 4 Ds" suggested for higher institutions in facing the pandemic situation (17): "Discover" the situation by getting all possible information; "Decide" on plans of action without waiting for all possible data to come in; "Design" a portfolio of actions which are realistic, quick, pragmatic and flexible; and "Deliver" the solutions in a systematic and organised manner. At the time of writing, the MCO have been considerably relaxed and final-year students are allowed to return to their respective medical faculties. The task force is cautiously optimistic that Recommendation 1 can be applied.

Tackling the emergent assessment issue has given the council valuable experience in inter-faculty communication and cooperation and hope that this will continue for the betterment of medical education in Malaysia.

\section{ACKNOWLEDGEMENTS}

The task force members would like to express their great appreciation to all medical education personnel in all public Malaysian medical faculties who were directly or indirectly involved with this task force.

\section{REFERENCES}

1. Reuters. Malaysia confirms first cases of coronavirus infection [Internet]. [cited 2020 June 14]. Available from: https://www. reuters.com/article/china-health-malaysia/ malaysia-confirms-first-cases-of-coronavirusinfection-idUSL4N29U03A 
2. Wikipedia. 2020 Malaysia movement control order [Internet]. [cited 2020 June 14]. Available from: https://en.wikipedia.org/ wiki/2020_Malaysia_movement_control_ order\#cite_note-MCO_contents-5

3. Crespo RM, Najjar J, Derntl M, Leony $\mathrm{D}$, Neumann S, Oberhuemer $\mathrm{P}$, et al. Aligning assessment with learning outcomes in outcome-based education. IEEE EDUCON 2010 Conference, Madrid. 2010;1239-46. https://doi.org/10.1109/ EDUCON.2010.5492385

4. Krathwohl DR. Theory into practice a revision of Bloom's taxonomy: an overview. 2010 [cited 2020 June 14]. Available from: https://www.tandfonline.com/action/ journalInformation?journalCode $=\mathrm{htip} 20$

5. Abdul Rahim AF. Guidelines for online assessment in emergency remote teaching during the COVID-19 pandemic. Education in Medicine Journal. 2020;12(2):61-70. https://doi.org/10.21315/eimj2020.12.2.6

6. Schüttpelz-Brauns K, Kadmon M, Kiessling C, Karay Y, Gestmann M, Kämmer JE. Identifying low test-taking effort during low-stakes tests with the new test-taking effort short scale (TESS) - development and psychometrics. BMC Med Educ. 2018;18(1):1-10. https://doi.org/10.1186/ s12909-018-1196-0

7. Malaysian Medical Council. Subcommittee on undergraduate medical education of the medical education committee, Malaysian Medical Council Standards for programme accreditation of undergraduate medical programmes contents [Internet]. 2019 [cited 2020 June 14]. Available from: https://mmc.gov.my/wp-content/ uploads/2019/12/STANDARDS-FORUNDERGRADUA TE-MEDICALEDUCATION-Version-1-Updated-on-17Dis-2019.pdf
8. Downing SM, Haladyna TM. Validity threats: overcoming interference with proposed interpretations of assessment data. Med Educ. 2004;38(3):327-33. https://doi. org/10.1046/j.1365-2923.2004.01777.x

9. Malaysian Medical Council. Malaysian Medical Council guideline for conduct of online examination for undergraduate medical programme during and after movement control order due to COVID-19 pandemic [Internet]. 2020 May 21 [cited 2020 June 14]. Available from: https:// mmc.gov.my/wp-content/uploads/2020/05/ MMC_GUIDELINE-FOR-CONDUCTOF-ONLINE-EXAMINATION-FORUNDERGRADUATE-MEDICALPROGRAMME-DURING-AND-AFTERMCO.pdf

10. Coverdale JH, Roberts LW, Balon R, Beresin EV, Louie AK, Guerrero APS, et al. Professional integrity and the role of medical students in professional self-regulation. Acad Psychiatry. 2016;40:525-9. https://doi. org/10.1007/s40596-016-0534-y

11. Benson R, Brack C. Online learning and assessment in higher education: a planning guide. UK: Woodhead Publishing Limited; 2010. https://doi.org/10.1016/B978-184334-577-0.50004-3

12. Indiana University of Pennsylvania. Best practices for on-line academic integrity [Internet]. [cited 26 April 2020]. Available from: https://iup.edu/itsupportcenter/ content-repository/academic-services/ moodle/best-practices-for-on-line-academicintegrity/

13. Nik-Ahmad-Zuky NL, Baharuddin KA, Rahim AFA. Online clinical teaching and learning for medical undergraduates during the COVID-19 pandemic: the Universiti Sains Malaysia (USM) experience. Education in Medicine Journal. 2020;12(2):75-80. https://doi.org/10.21315/ eimj2020.12.2.8 
14. Siddique H. Final-year medical students graduate early to fight COVID-19 [Internet]. 2020 March 20 [cited 2020 June 14]. Available from: https://www.theguardian. $\mathrm{com} /$ world/2020/mar/20/final-year-medicalstudents-graduate-early-fight-coronaviruscovid-19

15. Cole B. 10,000 Med school graduates in Italy skip final exam, get sent directly into health service to help fight COVID-19. Newsweek. 2020 March 18 [cited 2020 May 23]. Available from: https://www.newsweek. com/italy-coronavirus-covid-19-medicalstudents-1492996

16. Schuwirth L, van der Vleuten C, Durning SJ. What programmatic assessment in medical education can learn from health care. Perspect Med Educ. 2017;6(4):211-5. https://doi.org/10.1007/s40037-017-0345-1
17. Illanes P, Law J, Mendy A, Sanghvi S, Sarakatsannis J. Coronavirus' impact on higher education [Internet]. McKinsey \& Company. 2020 March 30 [cited 2020 April 15]. Available from: https://www.mckinsey. com/industries/public-sector/our-insights/ coronavirus-and-the-campus-how-can-ushigher-education-organize-to-respond 